J. Lake Sci. (湖泊科学), 2013, 25(3):386-391

http: //www.jlakes.org. E-mail : jlakes@niglas.ac.cn

(C) 2013 by Journal of Lake Sciences

\title{
群体大小对微囊藻细胞昼夜垂向迁移的影响”
}

\author{
罗永刚 ${ }^{1}$, 朱 伟 ${ }^{1,2}$, 李 明 $^{1}$, 代晓炫 ${ }^{1}$, 肖 曼 $^{1}$ \\ ( 1 : 河海大学环境学院,南京 210098) \\ ( 2 : 河海大学水资源高效利用与工程安全国家工程研究中心,南京 210098)
}

\begin{abstract}
摘 要: 针对群体形态对微囊藻昼夜间上浮下沉规律的影响问题, 利用柱状培养装置对室内培养的单细胞、群体细胞以 及在太湖采集的群体细胞进行了昼夜间分层观测实验,探讨了细胞形态对微囊藻垂向迁移的影响. 实验结果表明: 单细 胞表现出一定的昼夜迁移规律,但无论是室内培养群体细胞还是太湖采集的群体细胞,都未观察到显著的昼夜上浮下沉 的变化规律. 另一方面, 太湖采集的群体细胞表现出显著的漂浮特点. 由此认为, 室内培养的细胞与实际湖泊细胞之间存 在比重上的差异,群体的大小对于上浮有明显的影响.
\end{abstract}

关键词: 微囊藻;群体大小;垂向迁移;昼夜变化;太湖

\section{Effect of colony size on Microcystis diurnal vertical migration}

\author{
LUO Yonggang $^{1}$, ZHU Wei ${ }^{1,2}$, LI Ming ${ }^{1}$, DAI Xiaoxuan ${ }^{1} \&$ XIAO Man ${ }^{1}$
}

(1: College of Environment, Hohai University, Nanjing 210098, P. R. China)

(2: National Engineering Research Center of Water Resources Efficient Utilization and Engineering Safety, Hohai University, Nanjing 210098, P. R. China)

Abstract: The diurnal migration of Microcystis was studied using a cylindrical reactor to demonstrate how colony morphology affects the tendency of Microcystis cells to float or sink. Experiments were carried out using single cells and colonies from laboratory incubation and also colonies from Lake Taihu. Results showed that single cells had significant diurnal migration while this was apparently insignificant in colonies either from laboratory incubation or natural water. In contrast, colonies taken from Lake Taihu exhibited remarkable floating features. These were observed to be due to differences in specific gravity between cells from laboratory incubation and Lake Taihu. In addition, colony morphology affects significantly the upward movement of the cells.

Keywords: Microcystis; colony size; vertical movement; diurnal variation; Lake Taihu

近年来, 蓝藻水华频繁发生, 给湖泊的功能与生态系统造成了非常严重的影响:如水质恶化、产生大量 恶臭、生物多样性急剧降低、湖泊水功能显著下降, 尤其是微囊藻水华产生的藻毒素对水生生物、家畜以及 人类的危害 ${ }^{[1-3]}$ 已引起人们的高度关注.

水华发生与微囊藻细胞在水体表层的聚集有很大的关系. 一般认为微囊藻细胞能够改变自身浮力, 进 行垂直迁移, 以获取适宜的光能, 得到充足的营养盐, 使得它们在与其它藻类竞争时具有明显的优势 ${ }^{[4-5]}$. 孔 繁翔等认为蓝藻水华暴发具有 4 个阶段 ${ }^{[6]}$, 微囊藻上浮是水华暴发的关键阶段, 蓝藻只有上浮才会在水体 表面形成与空气隔离的藻团, 形成肉眼可见的水华. 在微囊藻上浮机理研究方面, Justin 等 $^{[7]}$ 发现微囊藻可 以通过 3 种方式调节自身的浮力:伪空胞的合成、伪空胞的破裂和细胞内镇重物的合成与消耗 ${ }^{[8-9]}$. 而伪空 胞一直被认为是微囊藻水华形成的浮力主要提供者 ${ }^{[9-10]}$.

Yamamoto 等 ${ }^{[11]}$ 通过实际湖泊调查认为,大群体在水华形成过程中起着非常重要的作用. 在对太湖的调 查中发现,微囊藻水华暴发时,飘浮在水面上的细胞 $95 \%$ 以上都以群体形式存在, 同时在大量聚集的情况

* 国家重点基础研究发展计划“973”项目(2012CB719804)、江苏省重点基金项目(BK2011025)、国家自然科学基金 项目 (51278165) 和江苏省水利科技项目 (2011069) 联合资助. 2012-03-19 收稿;2012-11-28 收修改稿. 罗永 刚,男,1987 年生,硕士研究生;E-mail: zhuweiteam. hhu@ gmail. com. 
下,表层的微囊藻细胞并不出现昼夜间下沉上浮的现象,而是始终聚集在水体的表层. 这说明野外藻的运动 不仅受到伪空胞和镇重物等自身因素的影响, 还可能与风生流、潮汐等的扰动有关, 且形成群体形态更易于 使其保持漂浮状态,从而造成水华暴发.

关于微囊藻上浮机理方面的研究较多关注于伪空胞及细胞镇重物的变化, 对于细胞形成群体以后对上 浮聚集所产生的影响还没有明确的解释. 由于微囊藻沉浮规律实测研究大多是在野外湖泊进行, 难以排除 水体运动、风生流等因素的影响. 本研究尽可能排除其他因素的干扰, 采用室内水柱培养实验的方法, 在静 止状态下实测微囊藻细胞的垂向迁移规律, 以期探究微囊藻浮沉过程中群体大小所产生的影响, 明确微囊 藻在水面聚集形成水华过程中群体的作用.

\section{1 材料与方法}

\section{1 材料}

室内微囊藻单细胞培养: 铜绿微囊藻( FACHB-469) 购自中国科学院水生生物研究所, 培养于 BG-11 培 养基中, 温度为 $25^{\circ} \mathrm{C}$, 光照度为 $3000 \mathrm{~lx}$, 光暗比为 $12 \mathrm{~h}: 12 \mathrm{~h}$, 这种培养方式得到的微囊藻以单细胞形态存在 (图 1a).

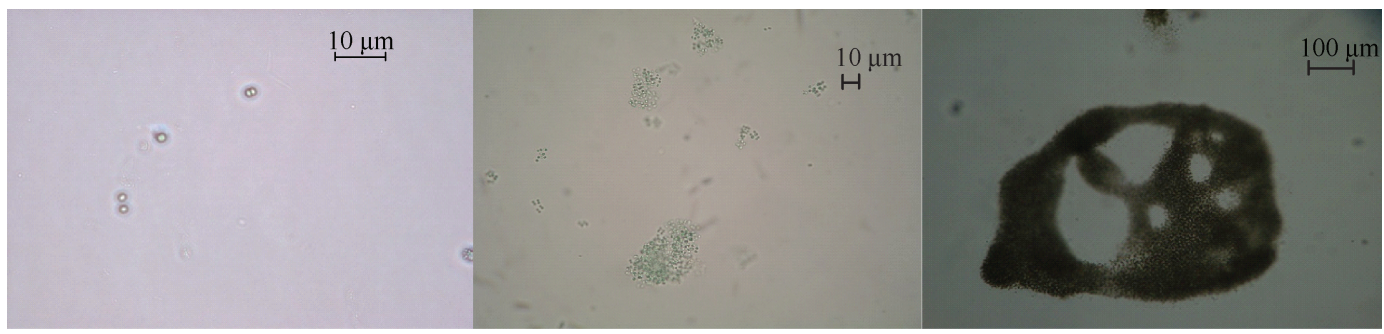

(a) 室内单细胞

(b) 室内群体

(c) 野外群体(2011年 8 月取于太湖梅梁湾)

图 1 实验藻种显微镜照片

Fig. 1 Microscopic photographs showing the various species of experimental microalgae

室内微囊藻群体培养: 根据长期的培养尝试, 摸索出群体形态的微囊藻细胞的培养方法, 即将铜绿微囊 藻单细胞接种于用锡纸包住的 $250 \mathrm{ml}$ 雉形瓶 (200 ml BG-11 培养基) 中, 初始接种密度为 $5 \times 10^{4} \mathrm{cells} / \mathrm{ml}$, 置 于培养箱在弱光条件下培养 $40 \mathrm{~d}$, 可得到直径为 $15 \sim 45 \mu \mathrm{m}$ 的微囊藻群体, 形态见图 $1 \mathrm{~b}$. 其他条件与微囊藻 单细胞培养条件相同.

野外微囊藻群体的获得:2011 年 8 月,在太湖蓝藻发生的阶段,于太湖 梅梁湾采集表层 $30 \mathrm{~cm}$ 的藻液,过 $63 \mu \mathrm{m}$ 浮游植物网富集,装瓶放人冷藏 箱带回实验室,形态见图 1c.

同时为了排除细胞的生理状态对实验结果的影响,本实验室已经采用 TTC -脱氢酶还原法对单细胞、培养 $40 \mathrm{~d}$ 的藻群体以及所采集的太湖野外 藻的活性进行了测定, 发现三者都具有较高的活性, 并且差异较小.

\section{2 水柱昼夜变化实验}

1) 实验装置: 采用高为 $1 \mathrm{~m}$ 、直径为 $0.14 \mathrm{~m}$ 的有机玻璃柱 (图 2 ), 用 黑色遮光纸将表面包住完全遮光,在距水体表面 $0 、 20 、 40 、 60 、 80 \mathrm{~cm}$ 处设 置取样口, 编号为 $1 \sim 5$, 实验水柱置于光照培养箱中.

2) 培养微囊藻单细胞与群体垂向分布实验: 先将藻种在培养箱中培 养, 待微囊藻生长进人指数期后, 经由注藻口将其移人实验装置. 将该水柱 装置置于温度为 $28^{\circ} \mathrm{C}$, 光照度为 $3000 \mathrm{~lx}$, 光暗比为 $12 \mathrm{~h}: 12 \mathrm{~h}$ 大型光照培养 箱内. 样品静置以防止培养液垂直搅动, 在水柱中培养 $7 \mathrm{~d}$ 后, 开始计测微 囊藻细胞昼夜垂向的变化. 每隔 $2 \mathrm{~h}$ 从垂向采样口采样, 计测持续 $24 \mathrm{~h}$. 分

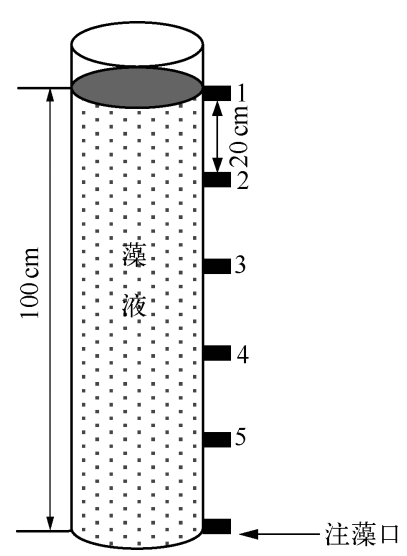

图 2 实验装置

Fig. 2 Experimental setup 
层获取的样品在奥林巴斯 C31 显微镜下用浮游植物计数板计数, 每个样品计数 3 次.

3) 太湖微囊藻的垂向分布实验: 将太湖采回的微囊藻群体过 160 目和 60 目笁, 把群体篮分为 $<100$ 、 $100 \sim 250$ 及 $>250 \mu \mathrm{m} 3$ 种. 将未经耖分的 1 种和经过篮分的 3 种不同群体大小的微囊藻也通过注藻口移人 水柱实验装置. 使用木棒轻轻地将微囊藻细胞在水中搅匀, 从静止开始在 $0.5 、 1 、 1.5 、 2 、 3 \mathrm{~h}$ 以后间隔 $2 \mathrm{~h}$ 从 垂向采样口采样, 持续计测 $24 \mathrm{~h}$, 计测微囊藻细胞密度在垂向上的变化.

\section{3 漂浮率计算方法}

为了表征微囊藻的上浮特征, 本文引人了 1 个变量—— “漂浮率 $\left(R_{i}\right)$, , 为所测该高度微囊藻的密度与 所测各深度微囊藻密度之和的比值, 即 $R_{i}=N_{i} / \sum_{1}^{5} N_{i}$, 式中 $N_{i}$ 为 $i$ 深度处的藻含量, 本实验共在 5 个深度 处取样.

\section{2 结果}

\section{1 培养微囊藻单细胞与群体藻密度随时间的垂向变化}

相对于群体细胞而言, 单细胞各层的细胞密度差异大, 变化幅度也大. 单细胞能够看出较为明显的昼夜 变化规律, 而群体细胞的规律不显著 (图 3). 表层 $20 \mathrm{~cm}$ 和下部 $80 \mathrm{~cm}$ 的细胞密度变化可以看出, 表层 $20 \mathrm{~cm}$ 处的微囊藻密度从 8:00 到 20:00 基本上处于波动上升状态,20:00 以后开始下降, 从 22:00 到次日 6:00 又 稍有增加. 而下层 $80 \mathrm{~cm}$ 处的变化趋势与表层 $20 \mathrm{~cm}$ 处的相反, 从 10:00 到 18:00 基本处于减少状态, 18:00 以后开始上升,到 $0: 00$ 变得最大,然后又开始下降(图 3a). 这说明单细胞状态下的表层细胞表现为白天上 浮、晚上下沉的变化规律. 变化幅度上, 表层 $20 \mathrm{~cm}$ 处藻密度从 $100 \times 10^{4} \mathrm{cells} / \mathrm{ml}$ 增加至 $300 \times 10^{4} \mathrm{cells} / \mathrm{ml}$ 左 右, 增减幅度在 3 倍左右. 室内培养的小群体微囊藻比较均匀地在水柱中分布, 似乎也能看到与单细胞较为 相似的变化规律, 但是变化范围很小 (图 3b), 上浮下沉的昼夜变化没有单细胞明显.

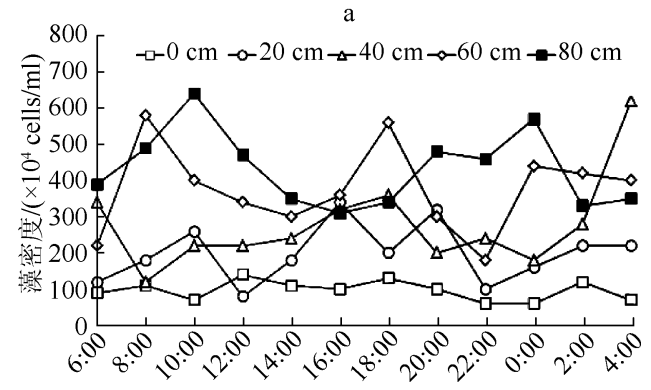

时间/h

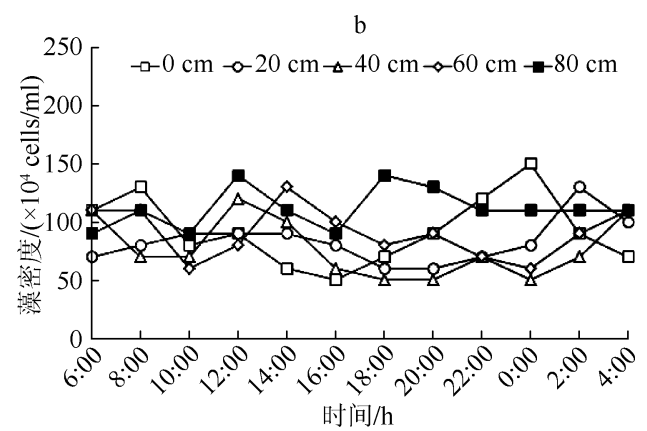

时间/h

图 3 铜绿微囊藻单细胞 (a) 与群体 (b) 密度随时间的垂向变化

Fig. 3 Vertical changes of single cell(a) and colony(b) density of Microcystis aeruginosa with time

微囊藻单细胞密度总体表现出下部较高、上部较低的分布规律, 群体细胞则表现出剖面上较为均匀的 分布规律 (图 4).8:00 时微囊藻细胞集中于 $60 \sim 80 \mathrm{~cm}$ 范围,到 16:00 则剖面上较为均匀, 说明下部的细胞 上浮到上部, 从 16:00 至 20:00, 微囊藻逐渐往中下层移动, 到次日 $0: 00$ 基本恢复了 8:00 的状态, 说明这期 间细胞发生了下沉, 到次日 4:00下部的细胞又出现明显向中层移动的现象 (图 4a). 但群体细胞这种垂向上 的变化不太明显(图 4b).

\section{2 太湖微囊藻群体藻密度随时间的垂向变化}

将采集于太湖、经篮分的微囊藻群体从底部注藻口注人实验水柱并搅匀后开始计测, 测得各层微囊藻细胞密 度(图 5). 无论群体大小, 微囊藻都出现了向表层 $1 \mathrm{~cm}$ 处大量聚集的结果, 水柱中只剩下 $10 \times 10^{4} \mathrm{cells} / \mathrm{ml}$ 以 下的微囊藻细胞呈均匀分布. 昼夜之间无明显变化, 此后处于培养状态 1 周, 微囊藻总是处于在表层聚集的 状态. 不同群体大小只是造成向表层聚集的时间出现了一些差异, 群体大的实验组, 能在短的时间内聚集于 表层, 而群体越小, 向表层聚集所需要的时间越长.

特征时段垂向群体细胞的分布情况见图 6,与图 5 所示的时间规律相同,各组数据都表明,在初始基本 

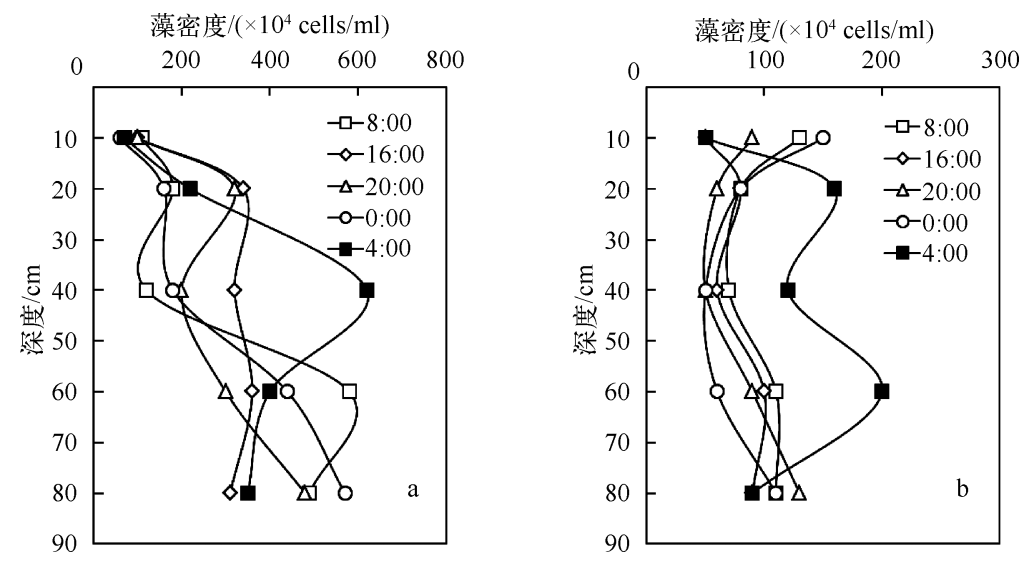

图 4 特征时段单细胞 (a) 与群体 (b) 藻密度随时间的垂向变化

Fig. 4 Vertical changes of single cell(a) and colony(b) density in specific period over the entire duration
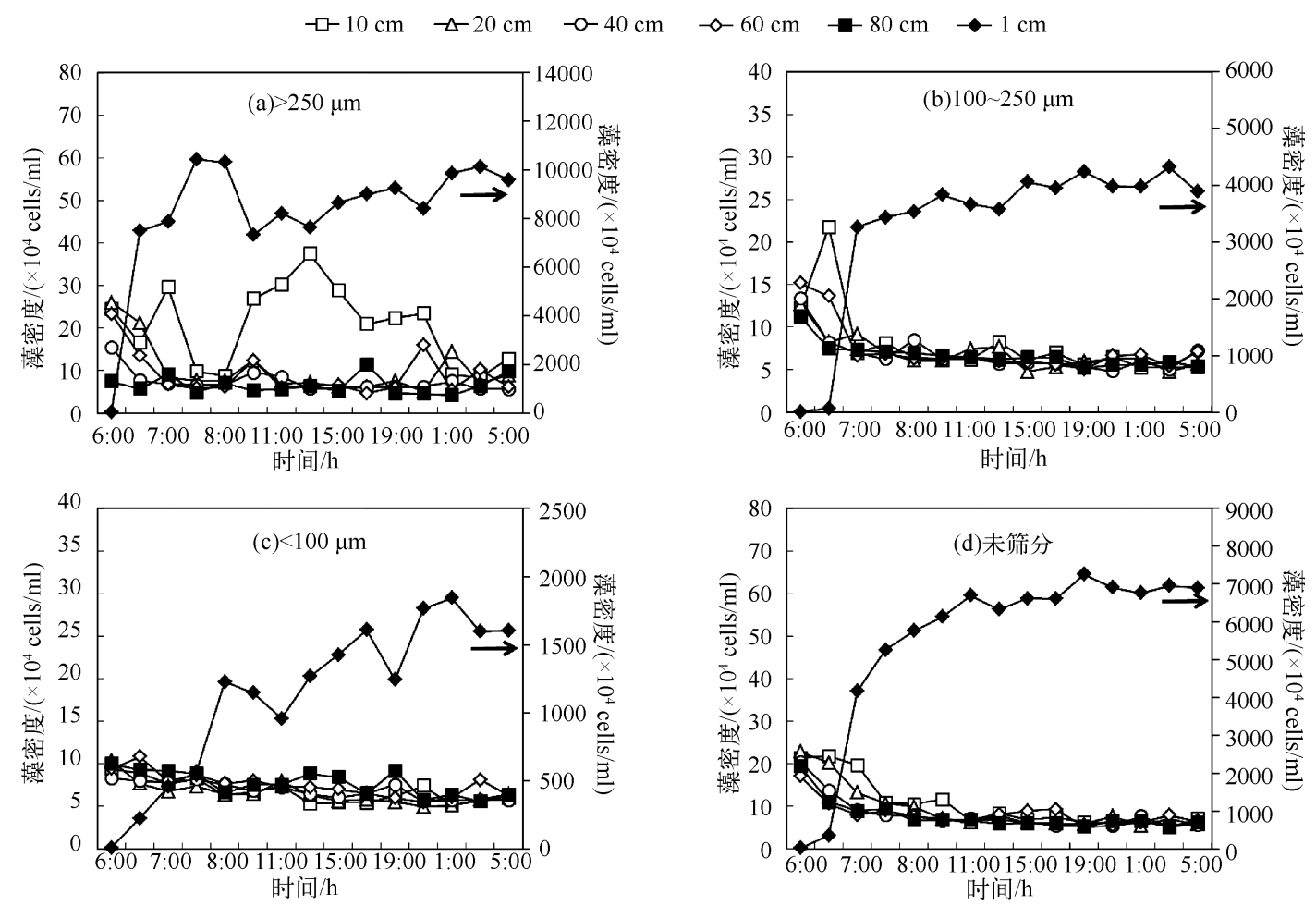

图 5 不同粒径的野外群体藻密度随时间的垂向变化

Fig. 5 Vertical variation in colony density of different sizes with time

混匀,垂向接近于均匀分布的条件下开始, 基本上在一小时内大部分细胞上浮聚集于水柱表面 $1 \mathrm{~cm}$ 的 范围内, 以下的水层中均匀分布数量较小的细胞, 其藻密度基本维持在 $10 \times 10^{4} \mathrm{cells} / \mathrm{ml}$ 以下. 而微囊 藻出现了明显的漂浮现象, 群体尺寸越大, 细胞漂浮率越大. $<100 \mu \mathrm{m}$ 的群体在 $2 \mathrm{~h}$ 时的漂浮率为 $64 \% ; 100 \sim 250 \mu \mathrm{m}$ 的群体在 $3 \mathrm{~h}$ 时的漂浮率为 $78.3 \% ;>250 \mu \mathrm{m}$ 的群体在 $0.5 \mathrm{~h}$ 时的漂浮率就达到 $89.7 \%$. 

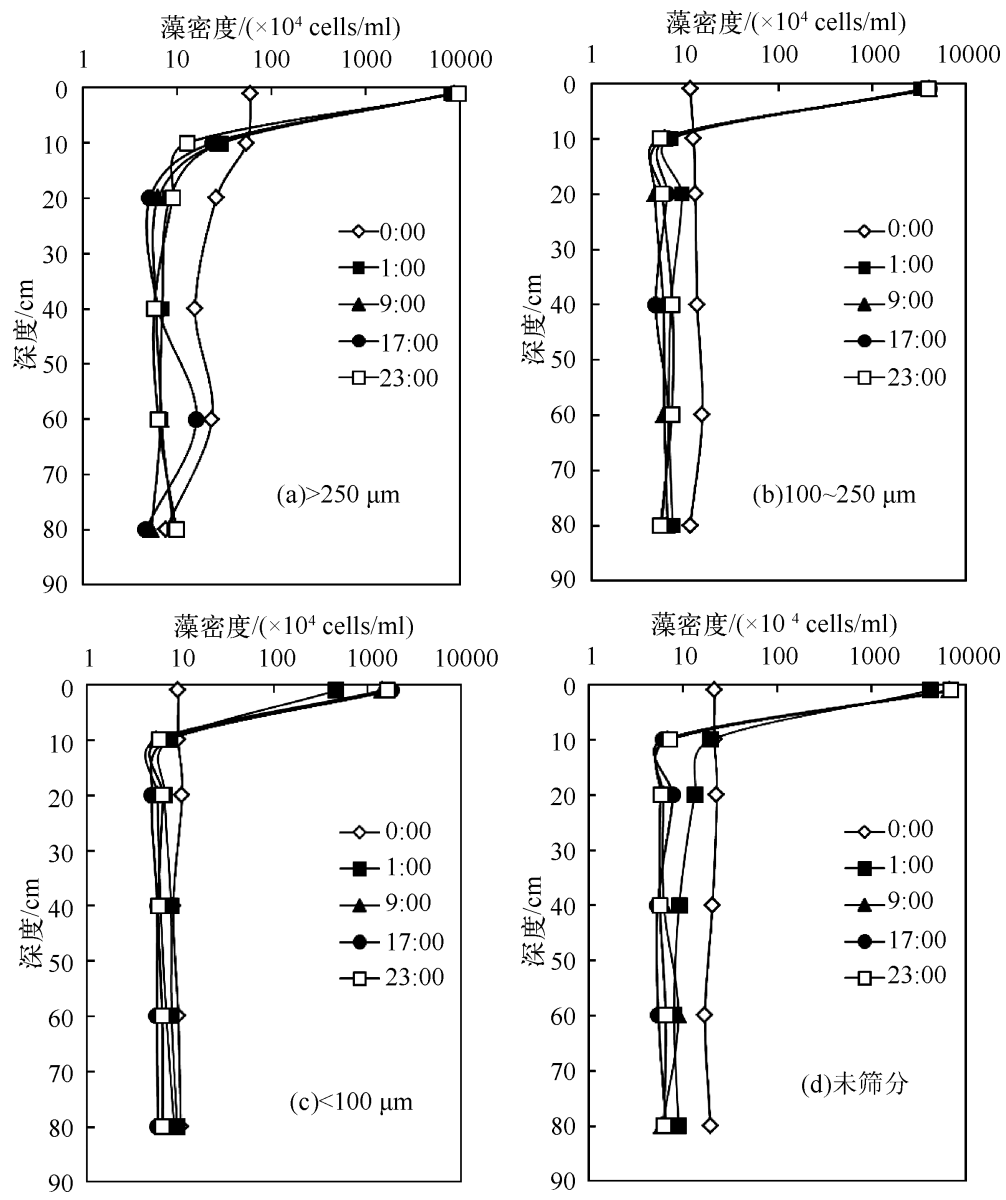

图 6 特征时段不同粒径的野外群体藻密度随时间的垂向变化

Fig. 6 Vertical variation in colony density of different sizes with specific period over the entire duration

\section{3 讨论}

微囊藻的重力密度是由细胞镇重物含量、伪空胞决定的 ${ }^{[12]}$, 在伪空胞充分发育的条件下, 微囊藻细胞的 比重一般在 0.985 左右,这在 Reynolds 等 ${ }^{[13]} 1975$ 年的研究中已经指出,而这一比重会随着伪空胞的破裂以 及淀粉类镇重物质的生成而增加. 伪空胞和镇重物质含量决定了微囊藻重力密度的大小, 当其小于水的重 力密度时, 微囊藻能够上浮聚集, 这是微囊藻形成水华的先决条件. 由于伪空胞破裂而导致浮力丧失迅速, 而且浮力恢复所需的伪空胞合成过程较慢 $(>24 \mathrm{~h})^{[14]}$, 细胞增殖对伪空胞的稀释作用也需要以细胞的世代 时间来度量, 可见伪空胞调节的响应时间较长, 因此在短时间内, 伪空胞体积变化对微囊藻上浮的影响较 小. 并且实际湖泊的实测总是受到风浪的影响, Takamura 等 ${ }^{[15]}$ 在 1984 年对霞浦湖 Takahamairi 湾的调查中 发现铜绿微囊藻下午集中在水体中部, 而晚上则聚集于水面, 从而认为风浪对微囊藻的上浮下沉有着一定 的影响. 本次实验是在完全静止的室内培养条件下进行观测, 发现基于室内培养的单细胞具有明显的昼间 上浮夜间下沉的过程,但这种过程随着群体的形成又变得非常模糊. 而从太湖采集的水华暴发时以群体形态 出现的微囊藻, 在上浮后基本漂浮于水面, 未能再观察到再下沉的现象. 因此可以认为, 室内单细胞微囊藻能 够产生上浮、下沉现象,但水华时湖泊的微囊藻更易于出现漂浮现象,这与对太湖的实际观察相同. 培养条件 不同的微囊藻之间出现的上浮下沉方面的差异与细胞比重、群体大小以及风浪的作用有着密切的关联.

从实验结果来看, 室内培养的单细胞易聚集在水柱的中底部, 其比重可能偏大; 室内培养的群体细胞较 
均匀地分布在水中, 比重可能稍小; 而太湖采集的群体微囊藻则能够全部漂浮于水面, 其比重最小. 在大多 数的室内培养中很难出现微囊藻的群体细胞, 只有大大降低细胞的生长率, 进行缓慢地培养, 才能培养出群 体细胞. 即使这样, 培养得到的群体细胞与太湖采集的群体细胞相比, 细胞密度和群体大小都远远不及. 这 可能是因为快速培养时, 由于营养等条件充分, 细胞易于合成淀粉类物质而比重较大, 实际湖泊中的生长比 培养实验要缓慢得多,因而形成的群体细胞比重要小一些.

另一方面, 群体的大小与上浮的速度有很大的关系, 一旦比重出现略低于水的情况, 大的群体上浮速度 要快的多. 从太湖群体细胞由均匀状态恢复到表层集中状态的速度来看, 大的群体要比小群体快得多. 本次 培养得到单细胞只有 $3 \sim 5 \mu \mathrm{m}$, 培养的群体尺寸为 $30 \mu \mathrm{m}$ 左右, 而太湖水华发生时的群体大都大于 $100 \mu \mathrm{m}$, 所以上浮能力更强.

\section{4 结论}

通过对室内培养的单细胞、群体细胞以及从太湖采集的群体细胞进行昼夜水柱培养实验,得到以下 结论.

1) 在 3 种微囊藻细胞中, 只有室内培养的单细胞表现出昼夜之间上下迁移的变化规律,即白天由中底 部向表层上浮,晚上从表层向中底部下沉.

2) 群体细胞均未出现明显的上浮下沉规律, 无论是室内培养, 还是采自太湖微囊藻群体都未观察到显著 的昼夜变化规律. 但室内培养的细胞群体趋向于在剖面上均匀分布, 而太湖的细胞群体显著地漂浮于表层.

3 ) 从细胞形态以及在水柱中的表现可以推测, 室内培养的单细胞比重较大, 室内培养的群体细胞次之, 而太湖的群体细胞比重最小.

4 ) 除细胞比重的变化会对上浮产生影响外,群体的大小对上浮速度具有更大的影响力.

\section{5 参考文献}

[ 1 ] Harada K. Recent advances of toxic cyanobacteria research. Journal of Health Science, 1999, 45(3): 150-165.

[ 2 ] Matsunaga H, Harada KI, Senma M et al. Possible cause of unnatural mass death of wild birds in a pond in Nishinomiya, Japan: Sudden appearance of toxic cyanobacteria. Natural Toxins, 1999, 7(2) : 81-85.

[ 3 ] Falconer IR, Toxic cyanobacterial bloom problems in Australian waters: Risks and impacts on human health. Phycologia, $2001,40(3): 228-233$.

[ 4 ] Oliver RL, Ganf GG. Freshwater blooms. The ecology of cyanobacteria. Netherlands: Springer, 2000 : $149-194$.

[ 5 ] Bonnet MP, Poulin M. Numerical modeling of the planktonic succession in a nutrient-rich reservoir: environmental and physiological factors leading to Microcystis aeruginosa dominance. Ecological Model, 2002, 156 : 93-112.

[6] 孔繁翔,高 光. 大型浅水富营养化湖泊中蓝藻水华形成机理的思考.生态学报,2005,25(3): 589-595.

[ 7 ] Justin DB, Geogre GG. Variations in the buoyancy response of Microcystis aeruginosa to nitrogen, phosphorus and light. Journal of Plankton Research, 2001, 23(12) : 1399-1411.

[ 8 ] Cheng HM, Qiu BS. Cyanobacterial gas vesicles and their regulation on the vertical distribution of cyanobacteria in water body. Plant Physiology Communications, 2006, 42(5) : 974-980.

[ 9 ] Walsby AE. Homeostasis in buoyancy regulation by planktonic cyanobacteria. FEMS Symposium, 1988, 44: 99-116.

[10] Walsby AE. Gas vesicles. Microbiology Reviews, 1994, 58: 94-144.

[11] Yamamoto Y, Shiah FK, Chen YL. Importance of large colony formation in bloom-forming cyanobacteria to dominate in eutrophic ponds. Cambridge: Cambridge University Press, 2011.

[12] Zhao SC, Xiang GJ, Bo Y et al. Buoyancy regulation of Microcystis flos-aquae during phosphorus-limited and nitrogen-limited growth. Journal of Plankton Research, 2007, 29(9) : 739-745.

[13] Reynolds CS, Walsby AE. Water-blooms. Biol Rev, 1975, 50 : 437-481.

[14] Hayes PK, Walsby AE. An investigation into the recycling of gas vesicle protein derived from collapsed gas vesicles. Journal of General Microbiology, 1984, 130: 1591-1596.

[15] Takamura N, Yasuno M, Sugahara K. Overwintering of Microcystis aeruginosa Kütz. in a shallow lake. Journal of Plankton Research, 1984, 6(6): 1019-1029. 